\title{
Total Systems Cost: A Better Metric for Valuing Electricity in Supply Network Planning and Decision-Making
}

\author{
S. Byrom ${ }^{1,2 *}$, A. Boston ${ }^{3}$, G. Bongers ${ }^{2}$, P. Dargusch ${ }^{1}$, A. Garnett ${ }^{4}$, and N. Bongers ${ }^{2}$ \\ ${ }^{I}$ School of Earth and Environmental Sciences, University of Queensland, St Lucia, Queensland 4072, Australia \\ ${ }^{2}$ Gamma Energy Technology, Eatons Hill, Queensland 4037, Australia \\ ${ }^{3}$ Red Vector, Loughborough, Leicestershire LE11, United Kingdom \\ ${ }^{4}$ Centre for Natural Gas, University of Queensland, St Lucia QLD 4072, Australia
}

Received 28 January 2021; revised 08 February 2021; accepted 17 March 2021; published online 20 April 2021

\begin{abstract}
Comparing the cost and value of electricity generation technologies is becoming more complex as electricity grids become more diverse. The changing generation mix, along with the need to maintain a competent grid, is resulting in previously acceptable cost comparison metrics being used outside of their limited range of applicability. In particular Levelised Cost of Energy (LCOE), if used to evaluate options for a future, low carbon grid, could result in erroneous and misleading conclusions. Electricity generation facilities do not only provide energy, they also provide an array of additional services which are fundamental to maintaining a permanent and reliable electricity supply across the system, including reserve capacity, and voltage and frequency control. Indeed, some technology options provide these services without generating any energy. These services, corresponding costs and operational implications need to be included in the evaluation of technologies in order to ensure the grids emerge transformed, resilient and genuinely sustainable. Total system cost and its derivative metrics are the most appropriate economic metrics for analysis and decision making in a future for low carbon grid.
\end{abstract}

Keywords: total system cost, grid security, cost metrics, levelised cost of electricity

\section{Introduction}

Contemporary electricity grids are rapidly transforming to enable the reliable delivery of low carbon electricity (Wei et al., 2019; International Energy Agency, 2020). This transformation is mainly driven by increased penetration of variable renewable energy (VRE) along with increases in consumer selfgeneration and the rise of battery energy storage (International Renewable Energy Agency (IRENA), 2017). Grids are also changing from largely centralised electricity generation systems to de-centralised and from unidirectional electricity flows to bidirectional flows (Hill et al., 2018; Ringkjøb et al., 2018). These factors make modelling future energy system more difficult. In this changing grid, politicians and planners need appropriate metrics to inform their choices for new and replacement generating assets. Traditional ways of evaluating a simple return for the investor may be inadequate for a planner, and the metrics used must evaluate the impact on the wider system.

Historically, Levelised Cost of Energy (LCOE) has been the most commonly used metric for evaluating different generation technologies. It has been described as a "useful tool" that is "primarily used by policymakers for long-term planning, as

" Corresponding author. Tel.: +61(7)-3365-6455; fax: +61(7)-3365-6899. E-mail address: s.byrom@uq.edu.au (S. Byrom).

ISSN: 2663-6859 print/2663-6867 online

(C) 2021 ISEIS All rights reserved. doi:10.3808/jeil.202100056 well as devising incentive mechanisms" (Raikar and Adamson, 2020), and "as way to measure holistically the costs that go into the production of a kilowatt-hour" (Huff, 2019).

However, as the generation mix of many electricity grids diversifies, LCOE becomes less useful; it is not a bad metric within its original context of an investor's view of similar, thermal plant, however it has slipped into usage for situations it cannot possibly be used to value. Not only does LCOE fail to capture costs and value that lie outside the power plant (Bindewald and Lynn, 2018), it also is often used to present the solution of the system planner or policy maker, which can be quite different to the solution of the investor who 'simply' needs to make a financial return. Electricity generation facilities do not only generate energy, some also provide a range of additional grid services which are essential for maintaining a permanent and stable electricity supply across the grid, including reserve capacity, voltage as well as frequency control (Heuberger et al., 2016; Australian Energy Market Operator (AEMO), 2020). These services and the corresponding costs and operational implications need to be included in the proper evaluation of electricity technology options in order to ensure the future electricity grid emerges transformed, resilient and genuinely sustainable.

The shortcomings of LCOE are well documented in literature. Pratama and MacDowell for the International Energy Agency Green House Gas describe the issue as: LCOE suffers from well-documented weaknesses and is widely regarded as 
being poorly suited to the heterogeneous electricity grid of the $21^{\text {st }}$ century (International Energy Agency Green House Gas (IEAGHG), 2020).

The U.S. Energy Information Agency (EIA) state that: The direct comparison of LCOE across technologies is often problematic and can be misleading as a method to assess the economic competitiveness of various generation alternatives because projected utilization rates, the existing resource mix, and capacity values can all vary dramatically across regions where new generation capacity may be needed (U.S. Energy Information Administration (EIA), 2018).

Heuberger et al. (2016) define the issue with LCOE as: The traditional concept of LCOE lacks a systems perspective when comparing the electricity generation costs for intermittent renewable energy sources and firm generation technologies, as it does not account for the costs imposed upon firm power generators (such as increased cycling and start-up costs) by intermittent power generators.

As a result of the inadequacies of LCOE as a first order metric, many have attempted to improve on this, or suggest a new metric all together. In this paper, we review the strengths and limitations of some selected existing evaluation metrics and particularly focus on total systems cost (TSC) as a useful framework for modelling a genuinely competent and sustainable electricity grid. TSC is the most appropriate cost metric in a changing grid for energy professionals and policy makers who need to understand the effect on those paying for the energy system, either directly by the consumer through bills or indirectly by the taxpayer through subsidy (Boston et al., 2017). This paper contributes to the existing literature by examining how TSC is a better way to evaluate power generation costs and introduces System Cost of Replacement Energy (SCoRE) and Carbon Abatement Cost (CAC). These are new metrics created to address the inadequacies of investor metrics, while including emissions reduction targets, addressing grid strength and maintaining the lowest total system cost.

\section{Features of 'Competent' Electricity Grid}

A 'competent' electricity grid is one that can 'keep the lights on' within the legislated tolerance for outages and performance. A competent grid is adequate, reliable, secure, operable and robust against externally driven disruptions.

In practice, the reliability of the electricity grid often seems to be taken for granted, however it is an essential element of the modern economy, and with a changing grid, becoming increasingly more important (U.S. Department of Energy (DOE), 2017). The standards of reliability used by electricity grid operators have traditionally focused on broad metrics such as frequency, and duration and extent of power outages, as most networks have been supplied by large generation facilities (Australian Energy Market Operator (AEMO), 2020).

Historically these generators were invariably synchronous machines, meaning they were locked magnetically into the grid itself and rotated at grid frequency, allowing them to address many of the elements of a competent grid, such as inertia and frequency response. As grids transform to a low-carbon future, the grid has an increasing amount of generation and storage facilities connected via inverters, and these non-synchronous technologies do not necessarily offer the full range of grid services provided by the plant they are replacing. When operating a competent grid, there are minimum technical requirements that must be maintained within the emerging lower grid emission intensity requirements (Australian Energy Market Operator (AEMO), 2019).

While some characteristics of electricity grids differ from region to region, the fundamental physics are universal for large alternating current (AC) power systems (Australian Energy Market Operator (AEMO), 2019). There are well understood technical challenges for system operators who manage systems with increasingly high levels of VRE (Australian Energy Market Operator (AEMO), 2019). The Electric Power Research Institute (EPRI) has recommended a set of market and technical solutions to address these challenges (Electric Power Research Institute (EPRI), 2019). A grid operator, responsible for maintaining system adequacy, generally has to meet a minimum standard. One such metric is the 'expected unserved energy', defined as the proportion of demand that is not satisfied due to the inability of the combined generation portfolio to deliver sufficient power (Australian Energy Market Commission (AEMC), 2019). This is normally set very low to ensure businesses and consumers are protected from disrupted electricity supply (O’Neil, 2017).

A grid also operates within the desired frequency quality (typically 50 or $60 \mathrm{~Hz} \pm 1 \%$ ) (National Grid ESO, 2020). It includes the grid being operable, flexible to changing conditions, and to resist and rapidly recover from disruptions. This includes the flexibility to meet planned and un-planned changes in demand and supply on the second-to-second through to dayto-day timescales. This flexibility includes the need for the occasional rapid generation response, changes in storage operations and demand reduction options.

Nuclear, coal, gas, solar photovoltaic (PV), solar thermal, wind, geothermal and so on, all have different advantages and disadvantages, as well as offer different services to the electricity grid, as shown in Table 1 (Based on Electric Power Research Institute (EPRI), 2015; Miller et al., 2017). When a decision needs to be made to build or replace a power plant, stakeholders have traditionally looked at the LCOE of the alternative generation options, which divides the capital cost of an installed technology by the kilowatt-hours $(\mathrm{kWh})$ it can produce over its lifetime, i.e., the metric assumes energy production is the only product of value. As shown by Table 1, however, it is clear that the current power generation metrics, which are largely based on simplified formulae to make quick comparison assessments, are no longer able to be used in isolation of the grid system.

In contrast, TSC is directly related to the total cost that needs to be recovered and evaluates a new technology within the context of the grid to which it is being added. If adding a technology compromises grid adequacy in some way and additional grid services need to be acquired, this is incorporated within the TSC metric (Boston et al., 2020). TSC can also measure the benefit of a technology that brings benefit to the grid 
Table 1. Services Provided per Technology
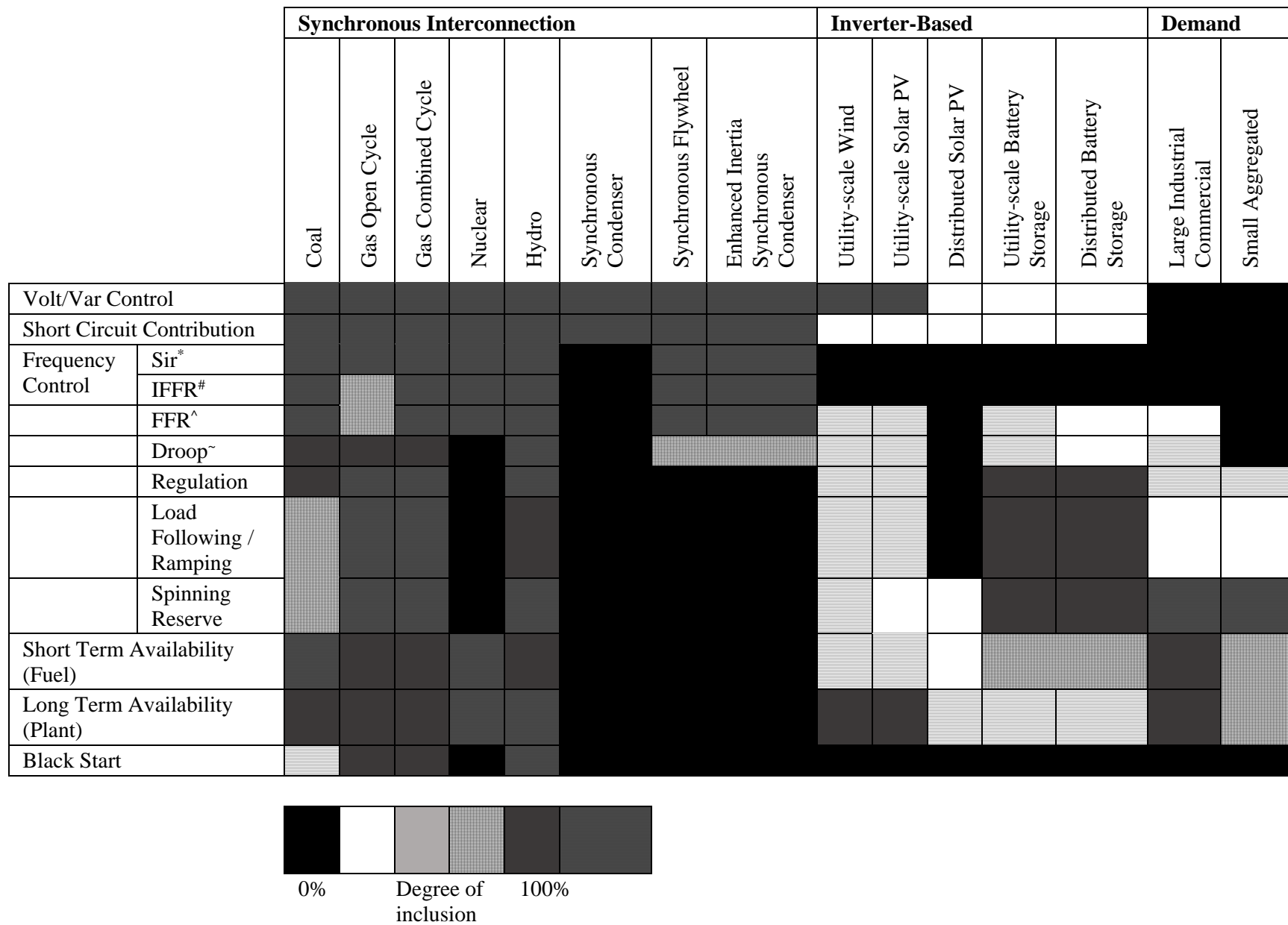

Notes: "SIR: Synchronous Inertial Response; \#IFFR: Inherent Fast Frequency Response; ^FFR: Programmed Fast Frequency Response; $D R O O P$ : Primary Frequency Response.

without producing energy (so its LCOE would be undefined) (Boston et al., 2020). In the following section, we review LCOE and other current technology generation metrics before discussing TSC and related metrics derived from this "consumer's eye view" of the economics of grid transformation.

\section{Current Generation Cost Comparison Metrics}

The majority of current generation cost comparison metrics address individual generation technologies. Only a few assess the characteristics of the complete grid system that the technology is joining.

Explanations of each cost metric are detailed in the following sections using the nomenclature detailed in Table 2. When technology is referred to within a metric, this refers to the specific technology for which costs are being evaluated.

\subsection{Levelised Cost of Energy}

LCOE is the most commonly used metric to evaluate alternative generation technologies. LCOE was initially imple- mented as a first-order comparison from the point of view of an investor of the competitiveness of similar thermal projects (International Renewable Energy Agency (IRENA), 2017). LCOE considers generated electricity as a standardised product, not accounting for when the electricity was produced, where the generation plant is in relation to demand, and how the electricity was produced (International Energy Agency (IEA), 2014). It assumes that all the value of the asset is vested in the energy produced and gives no value to other services consumed from or offered to the grid. The key parameters that feed into LCOE include capital cost, fuel cost, fixed and variable operating and maintenance costs, financing costs, capacity factor, as well as life span for each plant (Yoong, 2017). It is expressed as dollars per megawatt hour (Equation 1) (U.S. Department of Energy (DOE), 2015). LCOE is an equivalent constant real terms pre-tax price that a generator would have to earn over the project to break-even. LCOE ignores any value that can be attributed to the technology's ability to dispatch energy (dispatchability), grid services or access to transmission.

LCOE fails to consider system and regional impacts of various generation technologies (Joskow, 2011) and is there- 
fore inadequate for valuing technologies that are integrated into a grid with diverse types of generation. Additionally, LCOE does not capture the costs imposed on other grid users by VRE, making the direct comparison of LCOE across technologies misleading and problematic as a way of assessing the economic competitiveness of different power generation options (U.S. Energy Information Administration (EIA), 2019). LCOE completely fails to account for technologies that provide important services and yet deliver little or no energy to the grid, and for technologies that consume energy, such as storage, demand side management and synchronous condensers:

$$
L C O E^{S}=\frac{\sum_{y=1}^{n} \frac{\text { CAPEX }_{y}+\text { FOC }_{y}+\text { VOC }_{y}}{(1+r)^{y}}}{\sum_{y=1}^{n} \frac{E G_{y}}{(1+r)^{y}}}
$$

Equation 1 can often be simplified by further assuming:

- $\quad C A P E X$ is only expended before operation and is expressed as an overnight cost $C A P E X_{0}=C A P E X$.

- $\quad$ Fixed costs do not vary from year to year, $F O C_{y}=F O C$ for $y=1, n$.

- Variable costs do not vary from year to year, $V O C_{y}=V O C$ for $y=1, n$.

- $\quad$ Energy generated does not vary from year to year, $E G_{y}=$ $E G$ for $y=1, n$.

Defining a capital recovery factor $(C R F)$ as the proportion of capital to be repaid each year to pay off the initial outlay by the end of commercial life, with discount rate $r$, is presented below:

$C R F=\frac{r(1+r)^{n}}{(1+r)^{n}-1}$

This gives the following, more commonly used, simplified definition of LCOE:

$$
L C O E^{S}=\frac{C R F \times C A P E X+F O C}{E G}+V O C^{S}
$$

\subsection{Levelised Avoided Cost of Electricity}

EIA has attempted to augment LCOE, the investors' metric, to examine the energy and the capacity income that could be generated from a technology. Whereas LCOE is a metric for the technology cost, their metric, the Levelised Avoided Cost of Electricity (LACE) attempts to quantify the likely market income. It also recognises that firm capacity, as well as energy, has a value (U.S. Energy Information Administration (EIA), 2018).

The energy income is calculated as the marginal cost of dispatch during each period (i.e. the system marginal price), with each time period weighted by the hours of assumed operation in that period (Graham, 2018). The capacity income is calculated from the marginal cost of meeting system planning re- serves (i.e. a system marginal capacity cost) factored by the estimated capacity credit for each technology (Equation 4) (Graham, 2018).

\begin{tabular}{|c|c|}
\hline Term & Definition \\
\hline $\bar{a}$ & System assets from 1 to $a_{\max }$ \\
\hline$C A P E X_{y}$ & $\begin{array}{l}\text { Investment expenditures, or capex, of the } \\
\text { technology in year } y(\$)\end{array}$ \\
\hline$C C$ & Capacity credit of the technology (from 0 to 1 ) \\
\hline $\mathrm{CO}_{2}$ & $\mathrm{CO}_{2}$ emissions $(\mathrm{t})$ \\
\hline$C P$ & Capacity payment (\$/MW) \\
\hline$C R F$ & Capital recovery factor \\
\hline$C V$ & $\begin{array}{l}\text { Capacity value (availability weighted capacity } \\
\text { price) of the technology ( } \$ / \mathrm{MWh})\end{array}$ \\
\hline$E G_{y}$ & $\begin{array}{l}\text { Energy generation of the technology in year } y \\
\text { (MWh) }\end{array}$ \\
\hline EV & $\begin{array}{l}\text { The energy value (generation weighted SMP) of } \\
\text { the technology }(\$ / \mathrm{MWh})\end{array}$ \\
\hline$F O C_{y}$ & $\begin{array}{l}\text { Fixed operating costs of the technology in year } y \\
\text { (\$) }\end{array}$ \\
\hline$F V$ & $\begin{array}{l}\text { The flexibility value of the technology per unit of } \\
\text { output (\$/MWh) }\end{array}$ \\
\hline$H G_{t}$ & $\begin{array}{l}\text { Hours of generation of the technology in time } \\
\text { period } t(\mathrm{~h})\end{array}$ \\
\hline$I C^{s}$ & Integration cost $(\$ / \mathrm{MWh})$ \\
\hline$n$ & Commercial life of the plant (years) \\
\hline$r$ & Discount rate \\
\hline$R S C$ & $\begin{array}{l}\text { Residual system cost, i.e. cost of all of the system } \\
\text { that is not the technology }\end{array}$ \\
\hline$s$ & $\begin{array}{l}\text { Superscript denotes that costs are specific, i.e. in } \\
(\$ / M W h)\end{array}$ \\
\hline$S M P_{t}$ & $\begin{array}{l}\text { Mean system marginal price during period } t \\
(\$ / M W h)\end{array}$ \\
\hline$t$ & Time period within a year from 1 to $t_{\max }$ \\
\hline$T E G$ & $\begin{array}{l}\text { Total energy generated in the system by all } \\
\text { technologies }\end{array}$ \\
\hline$T S C, T S C^{s}$ & Total system cost $(\$)$, specific TSC $(\$ / M W h)$ \\
\hline$T S C_{0}, T S C_{a}$ & $\begin{array}{l}\text { Total system cost for a base case with none of the } \\
\text { technology added, with technology added (\$) }\end{array}$ \\
\hline$V O C_{y}$ & $\begin{array}{l}\text { Variable operating costs of the technology in year } y \\
\text { (\$) }\end{array}$ \\
\hline$y$ & $\begin{array}{l}\text { Year, where year } 0 \text { is the last year of construction } \\
\text { and year } 1 \text { is the first year of operation }\end{array}$ \\
\hline
\end{tabular}

Table 2. Cost Metric Nomenclature

In theory LACE (income) and LCOE (cost) can be used to find the net economic value of a technology as LACE minus LCOE should indicate profitability. However, calculating prices and generation by period is complex and requires a model of the total system.

LACE does not incorporate subsidies, emissions taxes, off-take agreements/power purchase agreements (PPAs), or markets with excess or tight supply. LACE also does not allow for the level of flexibility or other generation services be incorporated into the model. As with LCOE, LACE also fails to incorporate technologies such as demand side management and storage. The equation presented by EIA is to calculate LACE for a particular year, although there is no reason why it could 
not be extended using a discount rate in a similar manner to LCOE:

$L A C E^{S}=\frac{\sum_{t=1}^{t_{\max }}\left(S M P_{t} \times H G_{t}\right)+C P \times C C}{H G}$

\subsection{System Levelised Cost of Electricity}

The inadequacies of LCOE have driven many to seek to correct the metric for additional costs that are incurred within the system and therefore not included in LCOE. For example, the metric Enhanced LCOE uses power system modelling tools to compare synchronous and non-synchronous technologies with the same system conditions (Yoong, 2017). However, as there is no universally accepted definition for integration costs, this metric often proves challenging. Moreover, considering that no technology added to a system is independent, this metric has been criticised as being fraught with methodological errors, speculative assumptions and double cost-counting risks (Heptonstall et al., 2017). This section will focus on one such metric, System LCOE (SLCOE) proposed by Ueckerdt et al. (2013), that has a clear definition that can be examined.

SLCOE is defined as LCOE plus integration costs (Equation 5). The latter are calculated from the specific cost (i.e. the cost per MWh of generation) of the residual, non-renewable, part of the system which are expected to increase as a variable renewable technology is added:

$S L C O E^{S}=L C O E^{S}+I C^{S}$

According to Ueckerdt et al. (2013), the integration costs are due to five elements: (i) increased need for balancing, (ii) grid constraints and connection, (iii) adequacy/backup costs of firm capacity, (iv) lower load factors of thermal plant, and (v) curtailment of overproduction. Not all authors agree on this breakdown, some use different or fewer categories (Organisation for Economic Co-operation and Development, 2012; Holttinen et al., 2013), but this does not prevent the calculation of integration costs which can be done in a top-down manner (Equation 6). Integration costs are shown to be a function of the cost of the residual system (i.e., the system excluding the technology in question and a base case TSC for a system without the technology at all):

$I C=R S C-\frac{T E G-E G}{T E G} T S C_{0}$

Combining Equations 5 and 6 gives the following definition of $\operatorname{SLCOE}^{\mathrm{s}}$ (Equation 7):

$S L C O E^{S}=L C O E^{S}+\frac{R S C-T S C_{0}}{E G}-T S C_{0}^{S}$

Note that residual system cost (RSC) and TSC need calculating to derive SLCOE, and that SLCOE is, unlike LCOE, a function of the state of the system of which the technology is added.

\subsection{Levelised Cost of Dependable Electricity}

This metric aims to overcome the disparity between the characteristics of generation plant (in particular fossil vs. VRE) by pairing VRE with battery storage, open cycle gas turbines or pumped hydro energy storage (PHES) to deliver similar services as firm plant (Wilson, 2017). Wilson compares generation pairs that have a similar load factor using their LCoDE metric (Wilson, 2017). There is no published detail on how the pairing is achieved. However, once a pair is established, the calculation of LCoDE proceeds as for LCOE, but for the two technologies working together. In short, LCoDE is an investment metric and not adequate to evaluate the impact on overall systems costs of an additional plant added to an existing network.

\subsection{Value Adjusted Levelised Cost of Electricity}

In order to deliver the World Energy Outlook (WEO), the International Energy Agency (IEA) developed Value Adjusted Levelised Cost of Electricity (VALCOE) as part of their World Energy Model (WEM) (International Energy Agency (IEA), 2019). VALCOE makes three adjustments to LCOE: energy, capacity and flexibility, which are calculated from market data and from outputs of an hourly electricity market model (Yoong, 2017; Graham, 2018). The equation for VALCOE can be seen in Equation 8 (Yoong, 2017):

$$
\begin{aligned}
V A L C O E_{x}^{S}= & L C O E_{x}^{S}+\left(\overline{S M P}-E V_{x}\right) \\
& +\left(\overline{C V}-C V_{x}\right)+\left(\overline{F V}-F V_{x}\right)
\end{aligned}
$$

- Energy Adjustment: The difference between the generation weighted SMP and the mean SMP.

- Capacity Adjustment: The difference between the capacity income per unit of output and the system average.

- $\quad$ Energy Adjustment: The difference between the flexibility value $(\mathrm{FV})$ of a technology and the average.

These three adjustments require a model and market data to calculate. The IEA do not clearly define how the averages or the factors that determine capacity value (CV) and FV are calculated, the latter also requires market data and an unspecified function.

\subsection{Other Metrics}

Building on Enhanced LCOE, the Whole System Cost (WSC), developed by Imperial College London, determines system integration costs based on a series of predetermined scenarios to increase the uptake of low-carbon generation technologies (Strbac and Aunedi, 2016). The WSC of a power generation technology can be articulated as the sum of the LCOE of the technology and the corresponding system integration cost (Strbac and Aunedi, 2016). This metric is complex and re- 
quires an entire system model with various scenarios to determine the system integration component of each technology, which is calculated in relation to the integration costs of a nuclear power plant, chosen as an example of low-carbon generation technology (Strbac and Aunedi, 2016). WSC includes energy storage, however it is included as part of system integration costs and does not allow for storage to be optimised to reduce the total system cost. This is a similar criticism as for LCoDE.

The WSC metric builds on Enhanced LCOE through whole system modelling, using the Whole-electricity System Investment Model (WeSIM). WeSIM has further capabilities that optimise total system cost (refer to Section 4), however the WSC metric has not utilised these capabilities. While this metric addresses nearly all relevant aspects of a grid, it appears to be on the continuum between Enhanced LCOE and total system cost (refer to Section 4).

Levelised Cost of Generation (LCOG) is the weighted average cost of power generation using the LCOE formula, while Levelised Cost of Balancing (LCOB) incorporates capital and operating costs of VRE, additional curtailment losses and transmission (Yoong, 2017; Graham, 2018). The two metrics are combined to provide a new LCOE to the model. This approach has been formed to model $100 \%$ renewable grids (Blakers et al., 2017). The result is derived from a model that utilises PHES as the main source of services to the grid, along with the sporadic use of legacy coal and gas generation to charge PHES reservoirs (Blakers et al., 2017). There is no inclusion of the cost associated with restarting a mothballed plant or continuing these as spinning reserve. There is also no inclusion of weather data to simulate hydro capabilities in the future. LCOG and LCOB form metrics that build upon LCOE and have therefore embedded some of the inadequacies of the LCOE metric, such as the inability to represent the non-linear rise in costs as a technology is added. As a result, these metrics do not address all services required by a grid, and therefore falls short as an adequate metric.

\section{Total System Cost}

TSC is the most appropriate cost metric in a changing grid for energy professionals and policy makers who need to understand the effect on those paying for the energy system, either directly by the consumer through bills or indirectly by the taxpayer through subsidy (Boston et al., 2017). A policy maker or long-term system planner may be concerned, in the first instance, by consumers' bills and afford- ability of changes such as decarbonisation, rather than investors' returns (Boston et al., 2017). The latter is important, as investment may not take place if returns are poor, but this can be addressed by policy changes, regulation, market mechanisms and cross-subsidies. However, a suboptimal technology mix, once installed, cannot be so easily addressed once built into the system (Boston et al., 2017). Hence the minimisation of TSC, subject to meeting appropriate grid security and environmental standards, should be the primary concern in both the short- and long-term planning horizons.
A conceptual representation of TSC is provided in Figure 1 (Boston et al., 2020). Electricity system assets are shown within the system circle in the diagram and refer to physical parts of the system, such as generators and grid facilities. Costs refer to any payments that leave the electricity system, such as fuel costs shown by blue arrows, or taxes shown by green arrows. However, these costs exclude exchanges between participants of the system, such as a generator's grid connection fees or the system operator's payments for grid services shown by light blue arrows. The price paid by consumers, either directly or indirectly, (orange arrows) must cover all of these outgoings and hence is also, in the example represented in Figure 1, equal to TSC.

TSC takes a holistic approach and when used to compare the changes in a whole system it can derive the economic value of adding alternative power generation technologies (Boston et al., 2020). The TSC methodology is similar to cost benefit analysis, whereby the positive and negative effects of a new addition are all accounted for to determine the overall net cost or benefit to the grid (Yoong, 2017).

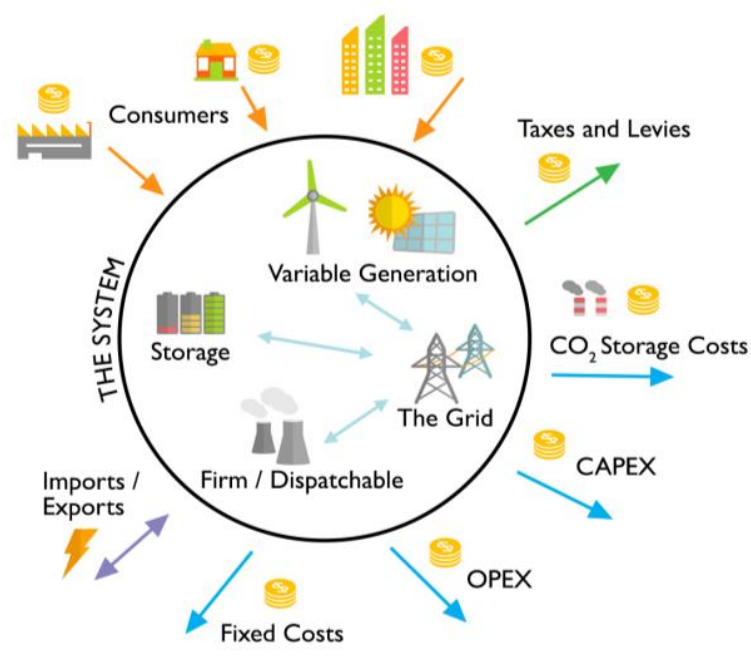

Figure 1. Derivation of total system cost as a function of external financial exchanges.

Modelling that uses TSC as the main metric is able to explore non-linear effects on cost. This is important as large amounts of curtailment, and hence costs, rise disproportionately as a technology starts to saturate the system (Boston et al., 2017). This leads to a technology having a different system cost for a first installation to the existing system than the $n^{\text {th }}$ capacity unit (International Energy Agency Green House Gas (IEAGHG), 2017). This is an important distinction, as the amount of one power generation technology capacity on a system can greatly affect the TSC, $\mathrm{CO}_{2}$ emissions and system strength.

The TSC for year y is shown in Equation 9:

$T S C_{y}=\sum_{a=1}^{a_{\max }}\left(C R F \times C A P E X_{a, y}+F O C_{a, y}+V O C_{a, y}\right)$ 
TSC is expressed in units of dollars or it can be divided by the annual demand for electricity on the grid and expressed in terms of average consumer cost of $\$ / \mathrm{MWh}$ (Heuberger et al., 2017a). It is important to note that this unit is not a proxy for wholesale electricity price and should not be interpreted as such.

Although TSC captures all the costs that customers and/or taxpayers pay via bills and subsidies, it does not immediately help distinguish between individual technologies on the grid. Three further metrics, derived from TSC, may help planners and policy makers do this, but have a more limited application. These are the Carbon Abatement Cost, System Cost of Replacement Electricity (SCoRE), and Levelised Value of Energy (LVOE), which are shown Sections 4.2 through 4.4.

\subsection{TSC Summary}

- Assumptions: Sufficient data exists to model the entire system.

- Useful for: Determining the effect of changes to the technology mix to consumer bills. Identifying which technologies reduce costs and which are expensive. Can be used for any grid technology.

- Limitations: Needs access to a grid model and expertise to operate.

\subsection{Carbon Abatement Cost}

$\mathrm{CAC}$ is a measure of the cost effectiveness of reducing carbon emissions via a particular action or set of actions. It is highly relevant to a system embedded in an economy that needs to decarbonise and can be readily compared to abatement costs elsewhere in the economy. The abatement cost is the change in TSC upon completion of the action, divided by the reduction in $\mathrm{CO}_{2}$ equivalent emissions for the same time period (Equation 10):

$C A C_{a}=\frac{T S C_{a}-T S C_{0}}{C O_{2_{0}}-C O_{2_{a}}}$

\section{Carbon Abatement Cost Summary:}

- Assumptions: Sufficient data exists to model the entire system. A costed action is being taken to reduce emissions.

- Useful for: Comparing the cost of an action in the electricity system with one elsewhere in the economy with the same aim of reducing emissions.

- Limitations: Needs access to a grid model and expertise to operate.

\subsection{System Cost of Replacement Energy}

When decarbonising a grid, a new power generation technology is often introduced to replace the energy delivered by a higher carbon generation technology (Gamma Energy Technology, 2020). In these circumstances, a metric is needed to compare the cost efficiency of different technologies. Ideally this is a specific metric (in $\$ / \mathrm{MWh}$ ) and particular to the tech- nology in question so it can be used in place of the original intent of LCOE. To achieve this, a legacy technology on the system has to be nominated as the technology that is to be replaced for all comparisons of alternatives. As a new technology is introduced, an amount of the legacy technology is removed from the system which is calculated to maintain a system security parameter, such as Loss of Load Hours (LOLH) or Unserved Energy (USE) at the same level (Gamma Energy Technology, 2020). Introduced here is the System Cost of Replacement Energy (SCoRE) that fulfils these criteria (Equation 11) (Gamma Energy Technology, 2020):

$S C o R E_{a}^{S}=\frac{T S C_{a}-T S C_{0}}{E G_{a}}$

System Cost of Replacement Energy Summary:

- Assumptions: Generation is being introduced to reduce emissions. The generation technology it is replacing is well defined. Only the energy production is valued.

- Useful for: Comparing different generation technologies which are being introduced solely to reduce emissions.

- Limitations: Needs access to a grid model and expertise to operate. It cannot measure the impact of technologies that provide little or no energy to the grid such as storage, demand side management, emergency standby plant, as well as plant to provide grid services.

\subsection{Levelised Value of Electricity}

The LVOE was introduced by Heuberger et al. (2016) to provide support to decision makers based on a more rigorous approach than using metric like LCOE. It is very similar to SCoRE but with an opposite signal that is a value rather than a cost and does not have a specification of a generation technology that is being replaced (Heuberger et al., 2016). Therefore, it can be used more generally than SCoRE for non-generation technologies but is less well defined in terms of constructing the new system from the base case. It is defined below in Equation 12 (Heuberger et al., 2016):

$L V O E_{a}=T S C_{0}-T S C_{a}$

Levelised Value of Electricity Summary:

- Assumptions: A pathway to the changed system is defined.

- Useful for: Comparing different generation technologies which are being introduced solely to reduce emissions.

- Limitations: Needs access to a grid model and expertise to operate. It cannot measure the impact of technologies that provide little or no energy to the grid such as storage, demand side management, emergency standby plant, and plant provide grid services (Heuberger et al., 2017b).

\section{Conclusions and Policy Implications}

Comparing the cost and value of electricity generation 
technologies is becoming more complex as electricity grids become more diverse with increased VRE penetration. The changing generation mix, along with the need to maintain a competent grid, is resulting in previously acceptable cost comparison metrics being less useful. Assessing the financial costs and benefits of a particular power generation technology in a diverse grid requires an integrative metric. Electricity supply is only one of the many services that technologies provide, or require from, the grid, which needs to be recognised in how technologies are valued and costed. Additionally, the existing grid that the new technology is being integrated into will significantly change the value of that technology. TSC is the most appropriate cost metric for a changing grid.

A comparison of selected cost metrics with reference to

Table 3. Key Metric Comparisons

\begin{tabular}{|c|c|c|c|c|c|c|c|c|c|c|c|c|}
\hline \multirow[b]{2}{*}{ METRIC } & \multicolumn{4}{|c|}{$\begin{array}{l}\text { Information Required to } \\
\text { Evaluate Metric }\end{array}$} & \multicolumn{5}{|c|}{ Metric Considerations } & \multirow[b]{2}{*}{ Assumptions } & \multirow[b]{2}{*}{ Use } & \multirow[b]{2}{*}{ Limitations } \\
\hline & 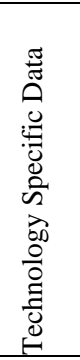 & 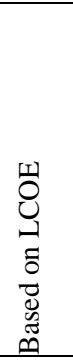 & $\begin{array}{l}\overline{0} \\
\bar{D} \\
\overline{0} \\
\overline{0}\end{array}$ &  & 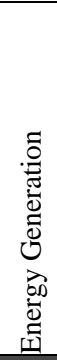 & 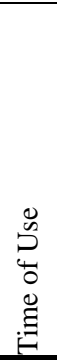 & 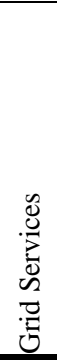 &  & 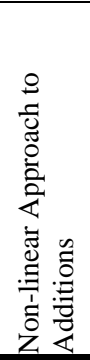 & & & \\
\hline LCOE & YES & YES & $\mathrm{NO}$ & $\mathrm{NO}$ & & & & & & $\begin{array}{l}\text { - All value in the } \\
\text { technology is } \\
\text { vested in the } \\
\text { energy produced. } \\
\text { - The timing and } \\
\text { location of the } \\
\text { delivery of that } \\
\text { energy is of no } \\
\text { consequence. } \\
\text { - Costs incurred } \\
\text { by the grid in } \\
\text { connecting or } \\
\text { supporting that } \\
\text { technology are } \\
\text { ignored. }\end{array}$ & $\begin{array}{l}\text { - An investor } \\
\text { calculating the } \\
\text { price of an offtake } \\
\text { contract when there } \\
\text { are no other income } \\
\text { streams. } \\
\text { - A planner } \\
\text { comparing two } \\
\text { plant with different } \\
\text { cost structures, but } \\
\text { almost identical } \\
\text { flexibility of } \\
\text { delivery and ability } \\
\text { to offer grid } \\
\text { services. }\end{array}$ & $\begin{array}{l}\text { - LCOE cannot } \\
\text { assess technologies } \\
\text { that provide little or } \\
\text { no energy, such as } \\
\text { storage, demand } \\
\text { side management, } \\
\text { and plant that } \\
\text { provide grid } \\
\text { services. } \\
\text { - It cannot be used } \\
\text { to compare } \\
\text { technologies } \\
\text { providing different } \\
\text { services or energy } \\
\text { delivery profiles, } \\
\text { such as flexible } \\
\text { hydro vs. inflexible } \\
\text { nuclear. }\end{array}$ \\
\hline LACE & YES & YES & $\mathrm{NO}$ & $\mathrm{NO}$ & & & & & & $\begin{array}{l}\text { - Income is only } \\
\text { derived from the } \\
\text { energy produced. } \\
\text { - Any other } \\
\text { benefits to the } \\
\text { grid or system } \\
\text { costs can be } \\
\text { ignored. } \\
\text { - The location of } \\
\text { the delivery of } \\
\text { that energy and } \\
\text { capacity is of no } \\
\text { consequence. }\end{array}$ & $\begin{array}{l}\text { - An investor } \\
\text { calculating the } \\
\text { likely income from } \\
\text { energy sales and } \\
\text { capacity } \\
\text { remuneration. } \\
\text { - An investor } \\
\text { combining LACE } \\
\text { with LCOE to } \\
\text { estimate } \\
\text { profitability of a } \\
\text { generation project. }\end{array}$ & $\begin{array}{l}\text { - LACE cannot } \\
\text { assess technologies } \\
\text { that provide little or } \\
\text { no energy to the } \\
\text { grid, such as } \\
\text { storage, demand } \\
\text { side management, } \\
\text { and plant provide } \\
\text { grid services. } \\
\text { - It cannot be used } \\
\text { to compare } \\
\text { technologies } \\
\text { providing different } \\
\text { services or different } \\
\text { energy delivery } \\
\text { profiles such as } \\
\text { wind vs. solar PV. } \\
\text { - It needs an } \\
\text { estimate of system } \\
\text { marginal price, } \\
\text { running hours and } \\
\text { the cost of the } \\
\text { marginal provider } \\
\text { of firm capacity. }\end{array}$ \\
\hline
\end{tabular}




\begin{tabular}{|c|c|c|c|c|c|c|c|}
\hline \multicolumn{8}{|c|}{ Continued } \\
\hline $\begin{array}{l}\text { SYSTEM } \\
\text { LCOE }\end{array}$ & YES & YES & YES & $\mathrm{NO}$ & $\begin{array}{l}\text { - Income is only } \\
\text { derived from the } \\
\text { energy } \\
\text { produced. } \\
\text { - Any other } \\
\text { benefits to the } \\
\text { grid or system } \\
\text { costs can be } \\
\text { ignored. } \\
\text { - The location of } \\
\text { the delivery of } \\
\text { that energy and } \\
\text { capacity is of no } \\
\text { consequence. } \\
\text { - Any other } \\
\text { benefits to the } \\
\text { grid or system } \\
\text { costs can be } \\
\text { ignored. }\end{array}$ & $\begin{array}{l}\text { - Comparing most } \\
\text { generation } \\
\text { technologies so long } \\
\text { as the system is well } \\
\text { understood. }\end{array}$ & $\begin{array}{l}\text { - It is dependent on } \\
\text { LCOE so cannot } \\
\text { assess technologies } \\
\text { that provide little or no } \\
\text { energy to the grid such } \\
\text { as storage, demand } \\
\text { side management, } \\
\text { emergency standby } \\
\text { plant, and plant } \\
\text { provide grid services. } \\
\text { - It requires modelling } \\
\text { the entire system to } \\
\text { estimate TSC }\end{array}$ \\
\hline VALCOE & YES & YES & YES & YES & $\begin{array}{l}\text { - The } \\
\text { technology } \\
\text { generates } \\
\text { energy. } \\
\text { - The location of } \\
\text { the delivery of } \\
\text { that energy is of } \\
\text { no consequence. } \\
\text { - Good market } \\
\text { data exists to } \\
\text { assess } \\
\text { flexibility. }\end{array}$ & $\begin{array}{l}\text { - Ranking the } \\
\text { usefulness of } \\
\text { generation } \\
\text { technologies to the } \\
\text { grid, i.e. the relative } \\
\text { ability to provide } \\
\text { energy, capacity and } \\
\text { flexibility, with a } \\
\text { more complete } \\
\text { assessment than } \\
\text { LCOE. }\end{array}$ & $\begin{array}{l}\text { - It is dependent on } \\
\text { LCOE so cannot } \\
\text { assess technologies } \\
\text { that provide little or no } \\
\text { energy to the grid such } \\
\text { as storage, demand } \\
\text { side management, } \\
\text { emergency standby } \\
\text { plant, and plant } \\
\text { provide grid services. } \\
\text { - All adjustments are } \\
\text { relative to an average } \\
\text { across all technologies } \\
\text { on the grid, so does not } \\
\text { give an absolute } \\
\text { measure of value or } \\
\text { cost. }\end{array}$ \\
\hline TSC & YES & NO & YES & NO & $\begin{array}{l}\text { - Sufficient data } \\
\text { exists to model } \\
\text { the entire } \\
\text { system. }\end{array}$ & $\begin{array}{l}\cdot \text { Determining the } \\
\text { effect of changes to } \\
\text { the technology mix } \\
\text { to consumer bills. } \\
\text { - Identifying which } \\
\text { technologies reduce } \\
\text { costs and which are } \\
\text { expensive. } \\
\text { - Can be used for } \\
\text { any grid technology. }\end{array}$ & $\begin{array}{l}\text { - Needs access to a } \\
\text { grid model and } \\
\text { expertise to operate. }\end{array}$ \\
\hline
\end{tabular}

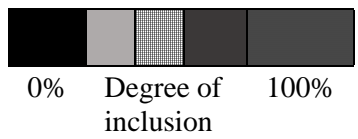

the information required to perform the evaluation and the various services incorporated within each metric is summarised in Table 3.

TSC is not a simple metric, but as the electricity grid is a complex orchestra of moving parts, a simple metric is not the answer. The characteristics of TSC and its ability to determine the value of a power generation technology makes it the most appropriate metric for assessing the financial impact of a technology on grid users. This metric essentially equates to a central planner's perspective to determine the least cost path for operation and investment. A technology's CAC or SCoRE, is better able to assess the value a technology can bring to an existing grid.

CAC and SCoRE are able to follow the strong non-linearities of grid economics. Using an invariant metric like LCOE will lead to inaccurate assessments of the set of technologies that will invariably not give the consumer the least-cost pathway to decarbonising the system, whilst leaving the grid inadequately supplied and insecure against disturbance.

The main argument of this paper is that TSC should be 
used by electricity supply planners and policymakers, as a key metric in their methods to evaluate future electricity grid configurations and electricity generation mixes. This is not a policy recommendation as much as it is a methodological method. The use of TSC should allow for a more nuanced design of electricity supply; one that will deliver a better balance of emissions reductions, cost and reliability.

Acknowledgements. This paper forms part of a $\mathrm{PhD}$ thesis for Stephanie Byrom, which is funded by Gamma Energy Technology. Geoffrey Bongers, Stephanie Byrom and Nathan Bongers have received funding for a portion of this work from Australian National Low Emissions Coal Research and Development (ANLEC R\&D). ANLEC R\&D had no role in study design; in the collection, analysis and interpretation of data; in the writing of the report; and in the decision to submit the article for publication.

\section{References}

Australian Energy Market Commission (AEMC) (2019). Definition of Unserved Energy, Final Report. Reliability Panel. https://www.aemc. gov.au/market-reviews-advice/definition-unserved-energy.

Australian Energy Market Operator (AEMO) (2019). Maintaining Power System Security with High Penetrations of Wind and Solar Generation (International Insights for Australia, Issue. A. E. M. O. (AEMO). https:// www.aemo.com.au/-/media/Files/Electricity/NEM/Security_and_Reliability/Future-Energy-Systems/2019/AEMO-RIS-InternationalReview-Oct-19.pdf.

Australian Energy Market Operator (AEMO) (2020). Ancillary services. https://aemo.com.au/en/energy-systems/electricity/national-electricity-market-nem/system-operations/ancillary-services.

Bindewald, G., and Lynn, K. (2018). Grid modernization initiative (GMI): briefing to the electricity advisory committee. National Rural Electric Cooperative Association. https://www.energy.gov/sites/prod/files/2018/ 07/f53/2.2\%20Grid\%20Modernization\%20Initiative\%20-\%20Bin dewald,\%20DOE0.pdf.

Blakers, A., Lu, B., and Stocks, M. (2017). 100\% renewable electricity in Australia. Energy, 133, 471-482. https://doi.org/10.1016/j.energy. 2017. 05.168

Boston, A., Bongers, G., Byrom, S., and Bongers, N. (2020). The Lowest Total System Cost NEM - the Impact of Constraints. G. E. T. P. Ltd. https://www.powerfactbook.com/downloads/energy-reports.

Boston, A., Bongers, G., Byrom, S., and Staffell, I. (2017). Managing Flexibility Whilst Decarbonising Electricity - the Australian NEM is hanging. G. E. T. P/L. https://www.powerfactbook.com/downloads/energy-reports.

Electric Power Research Institute (EPRI) (2015). Contributions of Supply and Demand Resources to Required Power System Reliability Services (3002006400). E. P. R. I. (EPRI). https://www.epri.com/research/ products/3002006400.

Electric Power Research Institute (EPRI) (2019). Activation of Distributed Energy Resources in the Energy Market Report. https://preprod. aemo.com.au/-/media/files/electricity/nem/der/2019/standards-protocols/epri-activation-of-der-in-the-energy-market-report. pdf?la=en\&hash=8A3BFCBEAAEF20ACBA15CB8DE6A3991B .

Gamma Energy Technology (2020). Power Generation Technology Cost Reference. https://www.powerfactbook.com/downloads/energy-reports? task=document. viewdoc\&id=35.

Graham, P. (2018). Review of Alternative Methods for Extending LCOE Calculations to Include Balancing Costs. CSIRO Australia.

Heptonstall, P., Gross, R., and Steiner, F. (2017). The Costs and Impacts of Intermittency - 2016 Update. U. E. R. Centre. https://www.research gate. net/publication/315106669_The_costs_and_impacts_of_intermitte
ncy_-_2016_update_A_systematic_review_of_the_evidence_on_ the_costs_and_impacts_of_intermittent_electricity_generation_ technologies.

Heuberger, C., Staffell, I., Shah, N., and MacDowell, N. (2017a). A systems approach to quantifying the value of power generation and energy storage technologies in future electricity networks. Computers \& Chemical Engineering, 107, 247-256. https://doi.org/10.1016/j.compch emeng .2017.05.012

Heuberger, C., Staffell, I., Shah, N., and MacDowell, N. (2017b). What is the value of CCS in the future energy system? Energy Procedia, 114, 7564-7572. https://doi.org/10.1016/j.egypro.2017.03.1888

Heuberger, C. F., Staffell, I., Shah, N., and MacDowell, N. (2016). Quantifying the value of CCS for the future electricity system. Energy \& Environmental Science, 9(8), 2497-2510. https://doi.org/10.1039/c6ee 01120a

Hill, B., Barr, R., and Parker, R. (2018). Cost, Reliability, and Emissions. Nuclear Power Solves the Australian Electricity Supply Trilemma. https://nuclearforclimate.com.au/wp-content/uploads/2018/09/ Solving-Australias-Energy-Trilemma.pdf.

Holttinen, H., O'Malley, M., Dillon, J., Flynn, D., Keane, A., Abildgaard, H., and Söder, L. (2013). Steps for a complete wind integration study. IEEE 2013 46th Hawaii International Conference on System Sciences, Maui, U.S.A. https://doi.org/10.1109/HICSS.2013.497

Huff, K.D. (2019). Chapter one - economics of advanced reactors and fuel cycles. In H. Bindra \& S. Revankar (Eds.), Storage and Hybridization of Nuclear Energy. https://doi.org/10.1016/B978-0-12-813975-2.0000 $1-6$

International Energy Agency (IEA) (2014). The Power of Transformation: Wind, Sun and the Economics of Flexible Power Systems. https:// doi.org/10.1787/9789264208032-en

International Energy Agency (IEA) (2019). World energy model. I. E. A. (IEA). https://www.iea.org/reports/world-energy-model.

International Energy Agency (IEA) (2020). World Energy Outlook 2020. IEA. https://www.iea.org/reports/world-energy-outlook-2020.

International Energy Agency Green House Gas (IEAGHG) (2017). Valuing Flexibility in CCS Power Plants (IEA GREENHOUSE GAS R\&D PROGRAMME, Issue. I. E. P. Ltd. https://ieaghg.org/exco_docs/201709.pdf.

International Energy Agency Green House Gas (IEAGHG) (2020). Beyond LCOE: Value of Technologies in Different Generation and Grid Scenarios (IEA GREENHOUSE GAS R\&D PROGRAMME, Issue. I. E. P. L. (IEAGHG). https://ieaghg.org/ccs-resources/blog/new-ieaghgreport-beyond-lcoe-value-of-technologies-in-different-generationand-grid-scenarios.

International Renewable Energy Agency (IRENA) (2017). Electricity Storage and Renewables: Costs and Markets to 2030. https://www. irena.org/publications.

Joskow, P.L. (2011). Comparing the costs of intermittent and dispatchable electricity generating technologies. American Economic Review: Papers \& Proceedings, 100(2), 238-241. https://doi.org/10.1257/aer. 100.3.238

Miller, N., Lew, D., and Piwko, R. (2017). Technology Capabilities for Fast Frequency Response. General Electric International (GE). https://www. aemo.com.au/-/media/Files/Electricity/NEM/Security_and_Reliability/Reports/2017/2017-03-10-GE-FFR-Advisory-Report-Final--2017-3-9.pdf.

National Grid ESO (2020). Frequency Response Services. https://www. nationalgrideso.com/industry-information/balancing-services/frequency-response-services.

O'Neil, A. (2017). What does "Unserved Energy" actually mean - a brief explainer. WattClarity. http://www.wattclarity.com.au/articles/2017/09/ what-does-unserved-energy-actually-mean-a-brief-explainer/.

Organisation for Economic Co-operation and Development (2012). Nuclear Energy and Renewables: System Effects in Low-carbon Elec - 
tricity Systems. https://www.oecd-nea.org/ndd/pubs/2012/7056-systemeffects.

Raikar, S., and Adamson, S. (2020). Renewable energy finance in the international context. In Renewable Energy Finance (pp. 185-220). https://doi.org/10.1016/C2017-0-04830-9

Ringkjøb, H.-K., Haugan, P.M., and Solbrekke, I.M. (2018). A review of modelling tools for energy and electricity systems with large shares of variable renewables. Renewable and Sustainable Energy Reviews, 96, 440-459. https://doi.org/10.1016/j.rser.2018.08.002

Strbac, G., and Aunedi, M. (2016). Whole-System Cost of Variable Renewables in Future GB Electricity System. I. C. London. https:// www.researchgate.net/publication/310400677_Wholesystem_cost _of_variable_renewables_in_future_GB_electricity_system.

U.S. Department of Energy (DOE) (2015). Levelized Cost of Electricity $(L C O E)$. U.S. Department of Energy (DOE) Office of Indian Energy. https://www.energy.gov/sites/prod/files/2015/08/f25/LCOE.pdf.

U.S. Department of Energy (DOE) (2017). Quadrennial Energy Review: Transforming the Nation's Electricity System: The Second Installment of the QER. https://www.energy.gov/sites/prod/files/2017/02/f34/
Quadrennial\%20Energy\%20Review--Second\%20\%20Installment $\% 20 \% 28$ Full\%20Report\%29.pdf.

U.S. Energy Information Administration (EIA) (2018). Levelized Cost and Levelized Avoided Cost of New Generation Resources in the Annual Energy Outlook 2018. https://www.eia.gov/outlooks/archive/aeo18/pdf/ electricity generation.pdf.

U.S. Energy Information Administration (EIA) (2019). Levelised Cost and Levelised Avoided Cost of New Generation Resources in the Annual Energy Outlook 2019. https://www.eia.gov/outlooks/archive/aeo19/pdf/ electricity_generation.pdf.

Ueckerdt, F., Hirth, L., Luderer, G., and Edenhofer, O. (2013). System LCOE: What are the costs of variable renewables? Energy, 63, 6175. https://doi.org/10.1016/j.energy.2013.10.072

Wilson, S. (2017). What are the Full System Costs of Renewable Energy? E. P. I. o. Australia. https://www.energypolicyinstitute.com.au.

Yoong, C. (2017). Valuing the Cost of Dispatchable and Non-Dispatchable Generation in a Transforming National Electricity Market. University of Queensland, Brisbane. 